ating the sharply angled hind margin. Plates of male once and a half the length of preceding segment, narrow and slender, very gradually narrowed to tips.

Described from several males and females collected at Los Angeles, Cal., by Prof. A. P. Morse, at Prescott, Ariz., by Dr. R. E. Kunze, and one specimen in the National Museum, taken at Los Angeles by Mr. Koebele. This, one of our prettiest Tettigonids, has long borne the above Ms. name of Dr. Uhler.

Tettigonia cythura n. sp. Length $\& 5$ $\mathrm{mm}$., of $\delta 4.25 \mathrm{~mm}$. Pale yellowish, dorsum and more or less of sternum, black. Face without distinct markings. Vertex with three black dots on front edge, one at center and one on either side; on either side of the disc, near front edge and parallel with it, is a black line which originates back of the point and terminates over the frontal suture; two fine median longitudinal lines on posterior half of disc, and a small spot on either side between ocellus and eye, black. Pronotum bright green, front margin yellow, broadening laterally. Scutel with the transverse impressed line and three very fine lines connecting it with hinder margin, black, causing the whole to appear like a black double loop on basal half. Elytra bright green by reflected light (smoky by transmitted) with a bluish tinge along the claval suture and base of costal margin, the principal veins more or less darkened, the apical margin transparent. Wings deep smoky.

Last ventral segment of the female twice the length of preceding, the hind margin acutely angled, the edge emarginate on either side of the acute point. Male plates of medium length, slender, narrowing to acute, slightly diverging, dark brown points.

Described from one female and numerous males, collected at Palm Springs, Cala., by Prof. A. P. Morse. I have one specimen from Arizona, received from the Cornell University collection. This fine little species has long borne the above Ms. name of Dr. Uhler.
Tettigonia aurora n. sp. Length of $q 7$ $\mathrm{mm}$. Pale yellowish, legs inclining to orange, dorsum bright carmine. Front with three longitudinal black lines nearly throughout its length on the disc, two abbreviated dashes above, and two dots on each lateral margin, one at antennal pit, the other at clypeal angle. A transverse row of three black spots on each gena. Clypeus with a dark median line. Front edge of vertex with three black dots, one at center and one on either side. Disc of vertex with a black line on either side, near and mostly parallel with front edge, extending from a short longitudinal dash near median line and just back of apex to the frontal suture; basal half of vertex with four equidistant rectangular spots, the two outer including the ocelli, the two inner somewhat elongate. Pronotum pale, slightly tinged with reddish posteriorly, with a row of six rectangular black spots near anterior margin, and a row of four smaller ones near hind margin; disc with four indistinct longitudinal lines. Scutel yellow, with the transverse impressed line, a median longitudinal stripe, and two dots at base black. Elytra brick red, the principal veins paler, the inner apical all transparent. Wings infuscated.

Last ventral segment of female twice the length of the preceding, hind margin broadly rounded.

Described from two females collected in Arizona and received from the Cornell University collection. This is another of Dr. Uhler's Ms. species, and the three are described under these names at his request.

\section{A NEW FORM OF PULVINARIA.}

BY G. B. KING AND T. D. A. COCKERELL.

Pulvinaria innumerabilis subsp. tiliae. subsp. nov.

․ Scale $6 \mathrm{~mm}$. long, 5 broad, 2 high, varying in size, sometimes as much as $8 \mathrm{~mm}$. 
long. Ovisac and form of insect as in innumerabilis. Body grey, with some lighter patches and black spots, giving a mottled appearance which is characteristic. Dried specimens become reddish-brown or greyish. Eggs white.

Antennae usually 7 -segmented, the several segments measuring as follows in $\mu \mu:-$ ( 1 ) 37. (2.) 39. (3.) 54. (4.) 68. (5.) 25 . (6.) I7. (7.) 42. Formula 4372I56. By the division of 4 , the antennae become 8-segmented, the measurements in $\mu \mu$ being :(I.) 39. (2.) 31. (3.) 56. (4.) 42. (5.) 25. (6.) 20. (7.) 23. (8.) 45. Formula 38412576. Of course these measurements vary more or less in different individuals. Legs ordinary; front leg with coxa 70 , femur I $_{2}^{2}$, tibia, II3 tarsus, 65, claw $20 \mu \mu$. All the digitules filiform, tarsal digitules very long. Marginal spines blunt, 34 to $37 \mu \mu$ long.

Hab.-On Tilia americana, Methuen, Lawrence and Andover, Mass., June 1898. (G. B. King). This insect is described as a subspecies of innumerabilis, because it is very closely allied to it, and evidently a comparatively recent segregate. It will probably be treated as a distinct species when the genus is revised. The mottled appearance is found by Mr. King to be constant and distinctive. The microscopical characters are nearly those of innumerabilis, but the antennal segments seem to be constantly shorter, and the marginal spines longer, than in that insect.

\section{JANET ON MYRMECOPHILOUS ANI- MALS.}

The literature upon myrmecophily is so extensive and scattered that a work which gives a general survey of the subject is certainly welcome. Such a desirable work is Janet's "Rapports des animaux myrmécophiles avec les fourmis" (Limoges 1897 , $8^{\circ}$, a pamphlet of nearly one hundred pages, dealing chiefly with insects, in a systematic and comprehensive way, although discussing also certain Nematodes, Isopods and Arachnids.

In view of the fact that almost thirteen hundred species of myrmecophilous animals are known, the work is necessarily concise, but the author has condensed a large amount of information into a comparatively small space and has wisely supplemented his statements at every step by references to original sources of information, which number two hundred titles. The results of other workers are well summarized and original observations abound throughout.

Those animals only are regarded as truly myrmecophilous which, for whatever reason, actually seek the society of ants and voluntarily come to live in their nests. From this definition, therefore, are excluded Aphids and Lycaenid larvae, certain enemies, enslaved ants and many insects which mimic ants. Janet considers these, indeed, but devotes special attention to true myrmecophily, comprising the following categories, each of which is examined in detail: parasitism; phoresy, denoting the utilization of ants for transportation; myrmecoclepty, signifying the theft of food from ants; synechtry, the consumption of ants as food; synoeky, to express the habits of such animals as enter ants' nests for debris, warmth, shelter, etc., have no direct relations with the ants themselves and are tolerated by the latter; and myrmecoxeny, a special kind of symbiosis.

Reserving the term symbiosis to imply mutual benefit, Janet suggests the word hamabiosis to signify the habitual dwelling together of two species, for any purpose, with or without evident advantage, either mutual or one-sided.

In this country, myrmecophily offers a large, fresh and fascinating subject for study, requiring not only minute observation and great patience but also considerable mechanical ingenuity. 

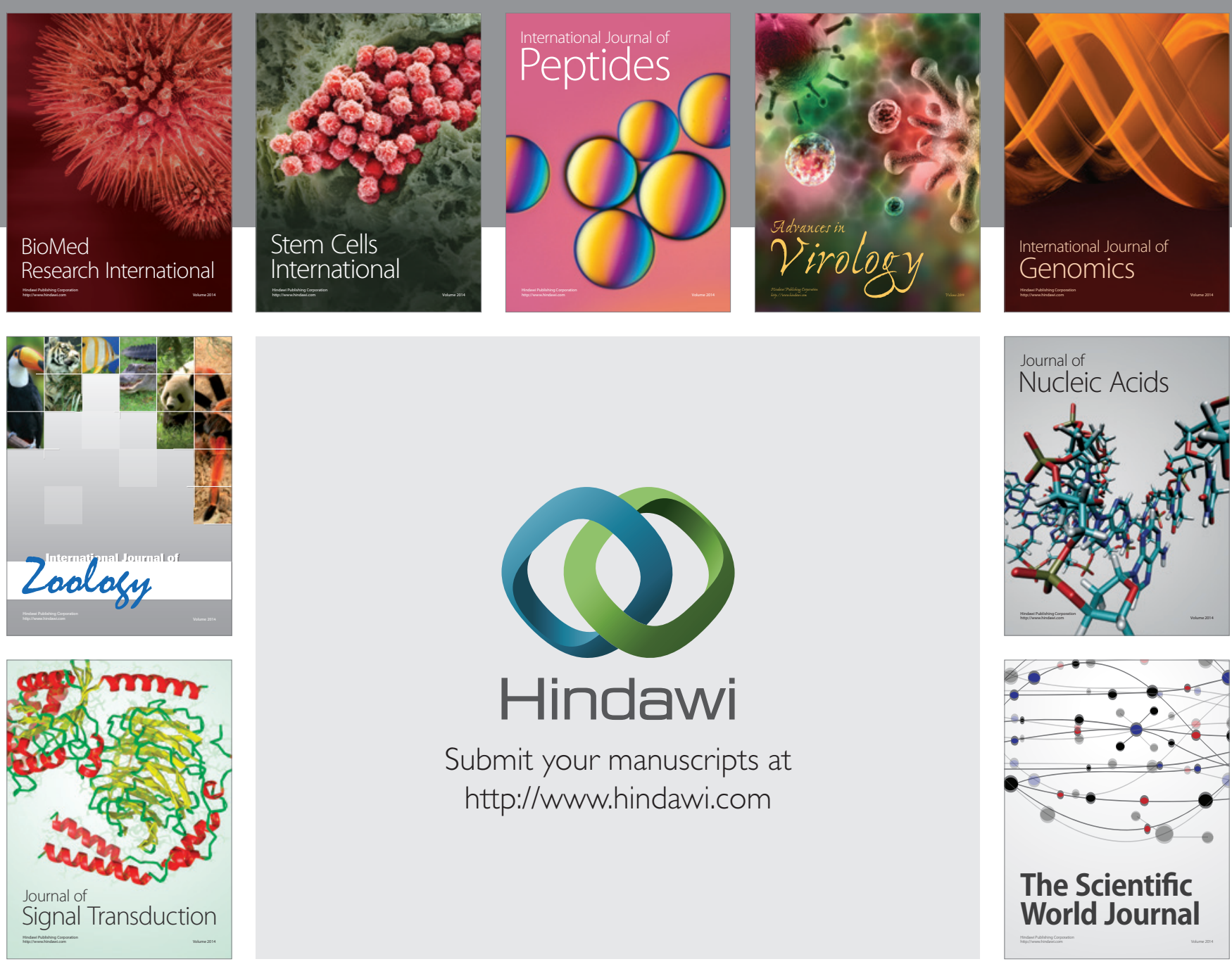

Submit your manuscripts at

http://www.hindawi.com
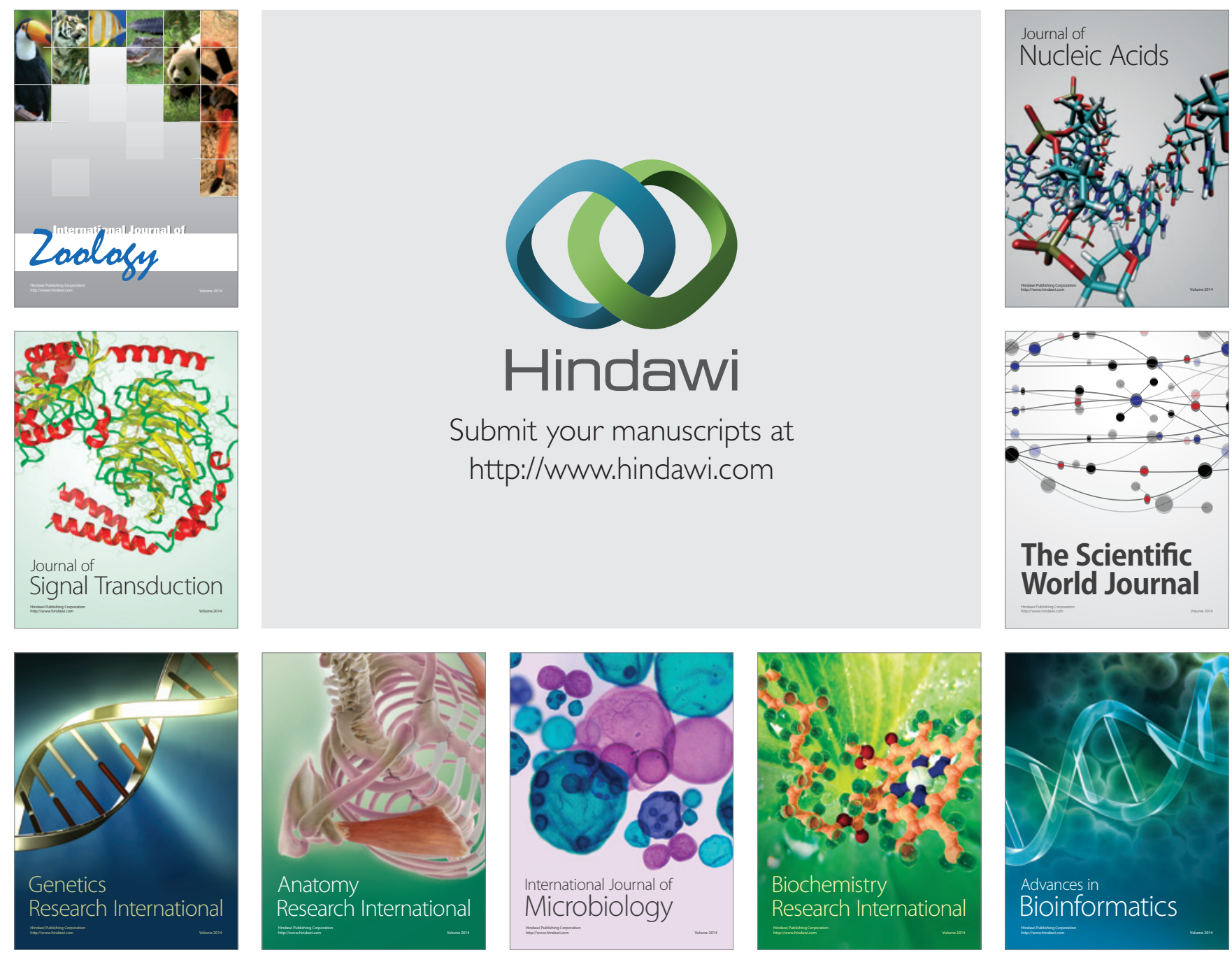

The Scientific World Journal
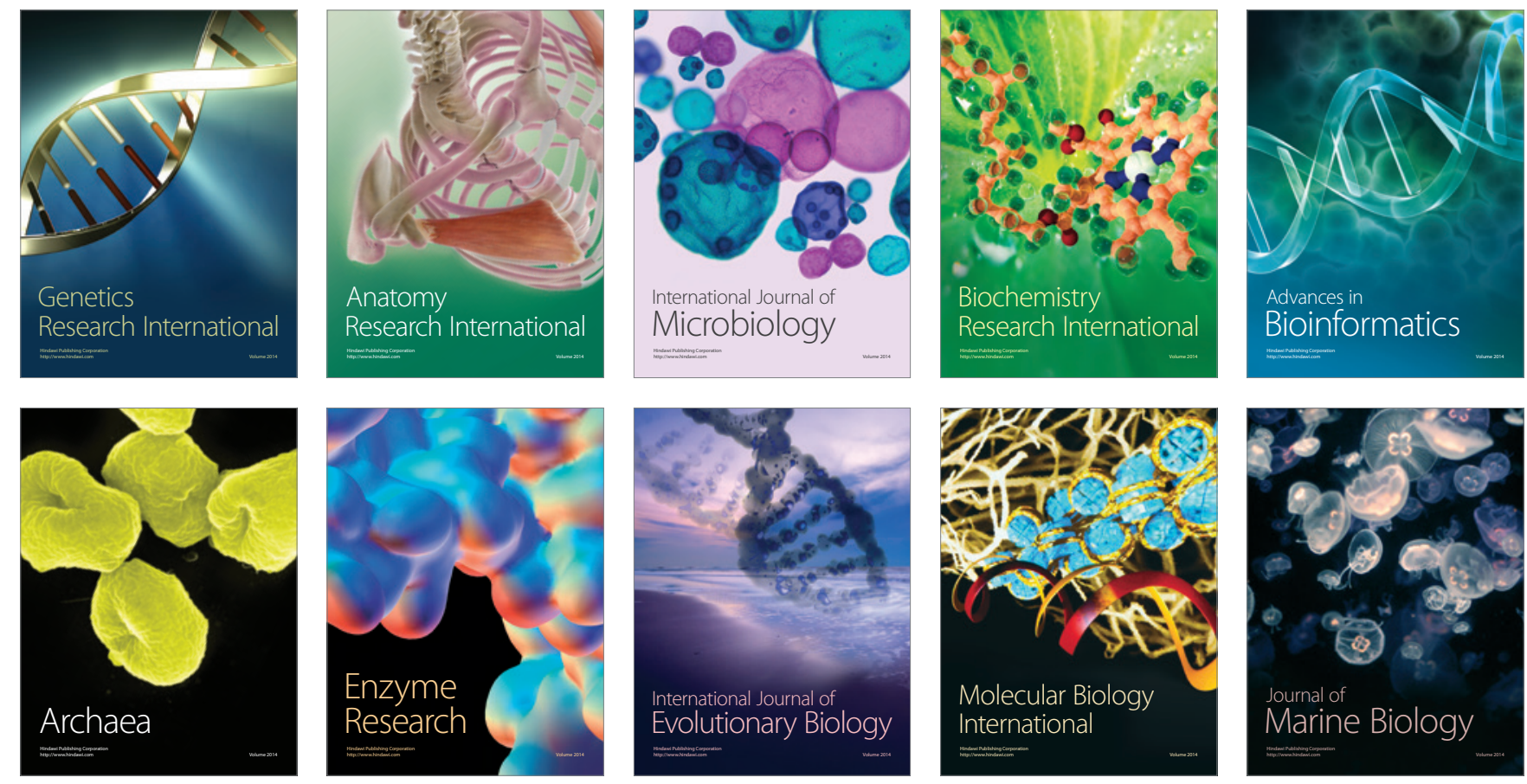